\title{
EL DOPAJE ENTENDIDO COMO TRAMPA PARA SACAR RÉDITOS DEPORTIVOS
}

\section{DOPING UNDERSTOOD AS A TRAP TO GET SPORTS WINS}

José Julio Goicochea Elías*

* Doctor en Derecho. Maestro en Derecho Civil y Comercial. Miembro Honorario de los Colegios de Abogados de Tacna, Cusco y la Selva Central. Orden al mérito Francisco de Paula Gonzales Vigil por el Colegio de Abogados de Tacna. Con ORCID: https://orcid.org/0000-0002-4735-8566

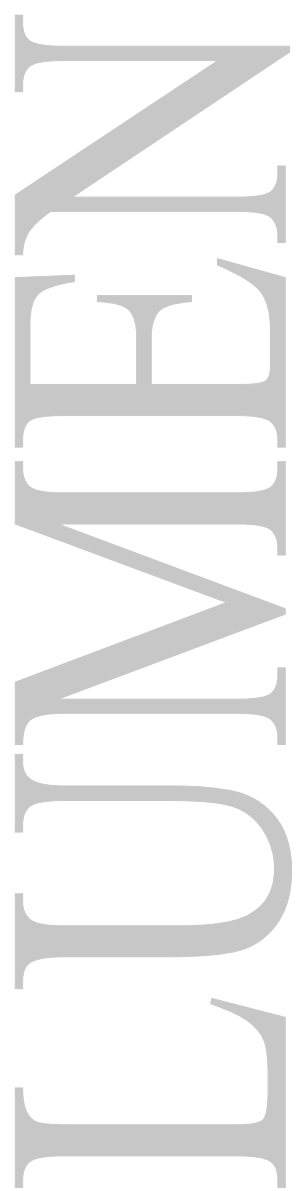




\title{
EL DOPAJE ENTENDIDO COMO TRAMPA PARA SACAR RÉDITOS DEPORTIVOS
}

\author{
DOPING UNDERSTOOD AS A TRAP TO \\ GET SPORTS WINS
}

José Julio Goicochea Elías

\begin{abstract}
RESUMEN
Los medios de comunicación masiva nos presentan cada vez con mayor frecuencia casos de deportistas que recurren al dopaje como una manera de conseguir ventaja en las competencias deportivas. Ello se presenta en la gran mayoría de veces debido a los sueldos cada vez más elevados y a las sumas que invierten las empresas en publicidad por concepto de imagen. Nadie quiere quedar segundo. Solo vale quedar primero. Tomando la frase orwelliana podemos decir que la historia la escriben los vencedores. Como contrapartida no dejamos de alarmarnos, cuando apreciamos como aquellos a los que teníamos como impecables campeones se veían luego como tramposos ídolos de barro a los que por un impensado descubrimiento, de manera merecida se les dejaba de rendir pleitesía.
\end{abstract}

\section{PALABRAS CLAVE}

Deporte, Dopaje, Salud, Juego Limpio, Medicina

\begin{abstract}
The mass media are increasingly presenting cases of athletes who resort to doping as a way to gain an advantage in sports competitions. This occurs in the vast majority of times due to the increasingly high salaries and the sums that companies invest in advertising for image concept. Nobody wants to be second. Only worth first. The glory is only written by the victors. As a counterpart we did not stop being alarmed, when we appreciated how those whom we had as impeccable champions were later seen as cheating mud idols who, by an unexpected discovery, deservedly ceased to pay homage.
\end{abstract}

\section{KEY WORDS}

Sports, Doping, Health, Fair Play, Medicine

\section{INTRODUCCIÓN}

El descubrimiento cada vez con mayor frecuencia de resultados y marcas deportivas que han sido obtenidos gracias a la ayuda del dopaje en los atletas, nos deriva a la eterna discusión metaética entre el deber ser donde la actividad volitiva del ser humano fluye libremente y el ser que se presenta como resultado de la actuación de una causa externa. Tengo la ilusión que este articulo académico pueda aportar en algo sobre este tema a pesar que un deporte tan profesionalizado (esponsoría y derechos de imagen incluidos) atente directamente contra esa ilusión.

\section{CONTENIDO DEL ARTÍCULO}

Santos Canelo Álvarez, Diego Armando Maradona, María Sharapova, Mariano Puerta, Alberto Contador, Gladys Tejeda, Paolo Guerrero, Romario, Ben Johnson, Lance Armstrong. Hablamos de deportistas famosos, multicampeones, pero todos ellos rociados con un denominador común: arrojaron positivo en los controles antidopaje que se les aplicaron y vieron empañadas sus trayectorias. No deja de ser irónico señalar que muchos casos no fueron considerados como dopaje a pesar de haberse detectado alteraciones en la sangre de los deportistas por el hecho de no saberse a ciencia cierta cuál era la sustancia que habíallevado a ello, por no tenerla registrada 
en ningún tipo de catálogo; lo que permite comprobar que las malas practicas empleadas en el doping, siguen estando por delante de los procedimientos para combatirlo y castigarlo. Si a ello le aunamos el hecho de que nadie puede ser sancionado por una conducta, que no se encuentre prevista en la ley con anterioridad a la comisión del hecho, podremos ir comprendiendo mejor el tema materia de análisis en el presente artículo.

\section{¿DE QUÉ VAMOS A HABLAR?}

Si indagamos por la definición que hace el Diccionario de la Real Academia de la Lengua Española del verbo dopar nos encontraríamos con la siguiente: "administrar fármacos o sustancias estimulantes para potenciar artificialmente el rendimiento del organismo, a veces con peligro para la salud". Si la trasladáramos al deporte, podemos señalar que el doping para la Conferencia Mundial sobre el Dopaje (1999) consiste en "... la utilización de un artificio (sustancia o método) potencialmente peligroso para la salud de los deportistas y/o susceptible de mejorar su rendimiento, o bien la presencia en el organismo de una sustancia o la constancia de la aplicación de un método que figure en las listas del Código Antidopaje del Movimiento Olímpico". Como se ve, ambas definiciones son muy parecidas con la salvedad que la segunda es más específica: se relaciona exclusivamente con el ámbito deportivo. En síntesis, podemos señalarlo como una moneda de cambio para obtener esa centésima de segundo que sirve de puente para la obtención de una medalla.

Rivero (2014) aporta sin embargo un concepto distinto que nos puede servir de guía para analizar el problema del dóping desde otros puntos de vista, que me parece importante reseñar antes de entrar a fondo en el tema que nos convoca para la redacción de este artículo

El dopaje es, sin duda un problema real e importante en el deporte mundial, pero es pocas veces tratado con la profundidad que requiere y es a menudo presentado en todos los ámbitos como una amenaza seria y fatal para el desarrollo del deporte profesional. Sin embargo, al enfocar toda la discusión sobre la ética deportiva en ese tema, se dejan de lado otros problemas que son, en mi opinión, más graves y acuciantes. Por ejemplo, se obvia deliberadamente la discusión profunda sobre el sexismo, la ideología machista y el tratamiento y la segregación de las minorías sexuales en el deporte. El dopaje se convierte así en la coartada ética de la dirigencia del deporte, mientras que otros temas acuciantes no se discuten ni se plantean, y en las contadas ocasiones en que son tratados se los analiza solo de manera superficial a partir de inveterados prejuicios genéricos (2014:23)

En ese orden de ideas, podríamos agregar antes de entrar de lleno al tema que nos convoca que en la vida cualquier profesional de éxito debe reunir dos condiciones: honestidad y capacidad. Lamentablemente ello no siempre se da. Se hace necesaria la formación de una escuela de dirigentes para formar a las nuevas generaciones que serán las encargadas de regir los destinos deportivos en un futuro no muy lejano.

\section{UN POCO DE HISTORIA}

Podemos señalar sin temor a equivocarnos que el dopaje es tan antiguo como la corrupción o la injusticia. El primer caso de dopaje deportivo del que se tiene conocimiento data de 1865 cuando se pudo detectar un uso generalizado de productos estimulantes entre los nadadores que participaron en una competición en el Canal de Ámsterdam. Las noticias de la época hacían a referencia a una droga de la cual no se tenia información previa que contribuía a aumentar la resistencia de los atletas en el evento deportivo. 


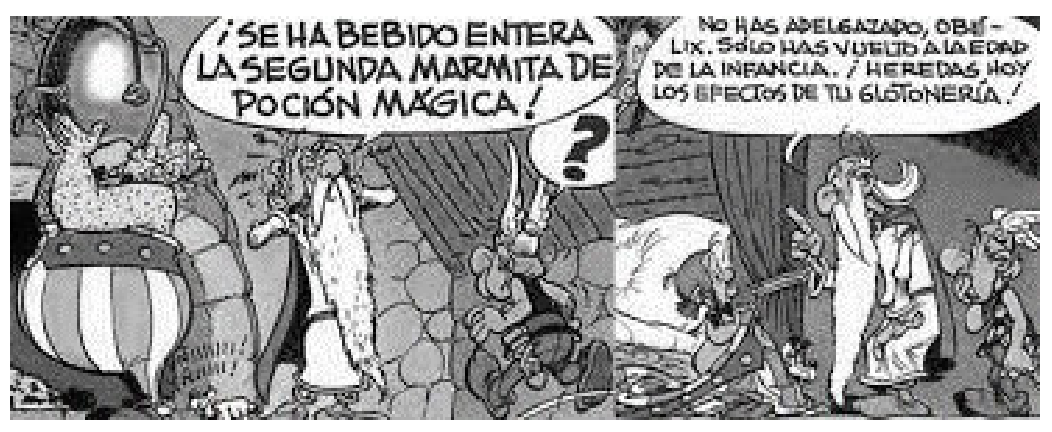

Ese fue el hito inicial (al menos conocido) de un problema del que todos opinan, pero pocos conocen a fondo. Sería bueno preguntarle a un deportista que se ha venido dopando y obteniendo logros deportivos por un buen periodo de tiempo al mejor estilo reporteril, que piensa de nuestro cuestionamiento a tan desleal práctica en las competiciones deportivas. Seguramente que se reiría en nuestra cara de nuestra pretendida filosofía deportiva enmarcada en los pedestales de la honradez y decencia; por la que le estaríamos pidiendo que renuncie a preseas, marcas, oportunidades de trabajo, contratos publicitarios y mejoras dentro del grupo social, por citar solamente algunos condicionamientos.

\section{LAS CONSECUENCIAS NEGATIVAS PARA LA SALUD Y LA INTEGRIDAD MORAL DE LOS DEPORTISTAS}

La relación indisoluble entre la medicina y la salud de los deportistas es incuestionable. Existen disciplinas donde los atletas por el desarrollo de su actividad sobrepasan el riesgo permitido como el boxeo, karate, rugby, fútbol americano etc., en las que se han producido lesiones incluso seguidas del resultado muerte. Siguiendo el razonamiento de Pérez Triviño (2017) tenemos que

incluso disciplinas que parecen más inocuas como por ejemplo la gimnasia, la halterofilia y tantos otros - pues no hay contacto físico-, llevan al organismo humano a los límites de exigencia. Y como se señalaba antes, en los últimos decenios se puede observar que esa misma actitud se ha trasladado al deporte aficionado e incluso al de los menores, de forma que no sea nada inhabitual que muchos de estos acudan a las consultas médicas como consecuencia de la práctica del deporte, muchas veces, entendido este de forma distorsionada. De ahí que algunos sostengamos que el deporte empieza donde la salud acaba. (p.41)

Estas situaciones han sido llevadas a la pantalla grande en el film La Verdad Oculta que cuenta con la participación del actor Will Smith. En dicha producción se dejan claros los intereses de los propietarios de las franquicias deportivas y su preponderancia sobre la salud de los deportistas que practican el futbol americano. Smith interpreta el papel del médico forense nigeriano Bennet Omalu, quien al practicarle una autopsia a Mike Webster futbolista de los Pittsburgh Steelers el 2002 le encuentra un trastorno cerebral que afectaba a varios de sus compañeros de profesión. El estudio que posteriormente realizará dicho profesional en los cerebros de otros atletas que perdieron la vida en circunstancias extrañas: Terry Long, Andre Waters y Justin Strzelczyk -quien fallece luego de tratar de escapar de la acción policial conduciendo su vehículo en sentido contrario en una carretera-, le permitieron demostrar que la Encefalopatía Traumática Crónica (ETC) se desarrollaba como consecuencia de los continuos golpes sufridos durante años en el transcurso de la práctica deportiva así como por el uso indiscriminado de fármacos.

Entre otras cosas por las cuales ha pasado a la historia el poeta romano Juvenal es por sus Sátiras. De una de ellas (Sátira X, 356) rescatamos la frase Orandum est ut sit mens sana in corpore sano (Debemos orar por una mente sana en un cuerpo sano). Ese es el ideal que no se debe perder. 


\title{
EL ROL FISCALIZADOR DE LA CIENCIA EN EL RENDIMIENTO DE LOS ATLETAS
}

\author{
González Viescas citado por Iturraspe e Iparraguirre (2011) señala que
}

Existe una estrecha vinculación entre "el derecho a la salud", la integridad de la persona, el desarrollo de actividades físicas y la práctica deportiva. (p.73).

El utilitarismo en materia deportiva, implica que las reglas han sido concebidas en bien del interés colectivo de los deportistas en las diferentes disciplinas que los cobijan y que no pueden ser vulneradas ni siquiera a escondidas con la cierta esperanza de que dichas conductas pasen desapercibidas. Si hay una lista de medicamentos no permitidos pues a respetarla, y si no, mejor que se dediquen a otra cosa. Si no les interesan los riesgos en que ponen a su salud, por lo menos que se preocupen en los derechos de sus colegas de profesión. Las reglas se han hecho para cumplirlas. El deporte se celebra con estadios y tribunas llenas, no en las cavernas del periodo neolítico donde imperaba la ley del más fuerte y la vida no valía nada. Sin embargo, también debo decir que el deporte es muy generoso, al respecto brinda oportunidades de trabajo diferenciadas.

Es obvio, que esta fuera de toda discusión que el deporte necesita de controles antidopaje. A ello nos ha llevado la gran cantidad de casos presentados sin distinción de fronteras ni deportistas. En los controles la visión que se tiene de los atletas es similar a la que pueda tener un fiscal o un juez penal sobre un presunto responsable en una causa penal. Me refiero al derecho de formulación constitucional que se refiere a la presunción de inocencia que representa que, en cualquier Estado civilizado de derecho, todos somos considerados inocentes hasta que se nos demuestre lo contrario. Por ende, debemos ser tratados como tales hasta que no se produzca un pronunciamiento definitivo (en última instancia) sobre nuestra responsabilidad. Si ello no ocurre, es claro que nos encontramos frente a una duda razonable. Ergo, es indispensable demostrar de manera irrefutable que el atleta es más que probablemente un culpable. En mi opinión, en la práctica no siempre ha ocurrido ello y pongo por ejemplo el caso del futbolista José Paolo Guerrero Gonzales que habría sido víctima mediante la ingesta de un té de coca de una contaminación cruzada. Baso mi opinión en varios factores: una trayectoria deportiva impecable; que no se haya demostrado fehacientemente que el agua del té esté contaminada; que el TAS (Tribunal de Arbitraje Deportivo) precise que fue culpa del deportista el hecho de no percatarse que era un mate de coca; que dos ex empleados del hotel donde se encontraba concentrada la selección peruana de fútbol Anthony Obando y Luis Escate señalaran en un programa televisivo que el atleta resulto contaminado accidentalmente; y más que eso: el hecho que no es creíble que un atleta cometa esa conducta a puertas de cerrar su brillante trayectoria deportiva debutando en un campeonato mundial de fútbol capitaneando a su representación nacional.

López citado por Pérez y Cañizares (2017) indica lo siguiente: Cabe preguntarse hasta qué punto está justificado tratar a deportistas que hacen su trabajo, sin haber sido acusados de ningún delito o falta, como criminales que han causado o que pueden causar un grave daño a la sociedad. (p.139).

Una de las columnas del derecho procesal la configura el maestro Francesco Carnelutti quien en sus Lecciones del Derecho Procesal Penal acotaba que el estado en modo alguno devolvía el estado de humillación a aquel procesado al que después de un entre comillas "debido proceso" en el que el Fiscal lo ametrallaba con preguntas inductivas (porque inducen a respuestas en un sentido determinado) se le declaraba inocente sin resarcirlo de modo alguno. Llevar a una persona a Tribunales a exponer "miserias humanas" es posicionarlo en una situación inferior con respecto al resto de mortales. El Gran Hermano procesaba. El Gran Hermano absolvía o como en la mayor frecuencia de veces: condenaba. 
Sin embargo, es distinta la situación que se presenta en la vereda opuesta. Podemos señalar que la afición deportiva quedo petrificada ante sus televisores cuando ante una pregunta que le hizo la entrevistadora Oprah Winfrey al multicampeón del Tour de France, Lance Armstrong interrogándolo acerca de si era probable que una persona que se drogara pudiera haber ganado dicha prueba ciclística (equivalente al campeonato mundial de ciclismo), en siete oportunidades, la respuesta fue brutal: NO. Pero cabe preguntarse porque aquellos que ocupaban los lugares inmediatos: segundo, tercero, cuarto, quinto no solicitaban ascender al puesto inmediato superior. Quien no la debe no la teme. Es sintomático que el Comité Olímpico Internacional conserve las muestras tomadas a los atletas por un periodo de diez años, con la finalidad de volverlas a revisar ya sea que se generen nuevos datos o se incorporen diferentes procedimientos de análisis a los que se llevaron a cabo durante la competencia.

En el deporte hay mucho velo de duda. Son demasiados los intereses que se encuentran en juego. Hay demasiado dinero de por medio. A esta altura cabe hacernos una pregunta: ¿si a Lance Armstrong no se le hizo ningún control antidopaje durante tantos años y competencias?; obvio que se le hicieron y fueron centenas.

¿Entonces porque nunca arrojaba positivo para el doping? Ello se daba por un tema de corrupción. Al deportista se le avisaba en que pruebas se iban a realizar los exámenes dos o tres días antes para que tuviera el tiempo necesario para poder limpiar su sangre. No debemos perder de vista que los ciclistas se aplican la droga durante los entrenamientos, nunca en la competencia. Es conocido en los corrillos deportivos que a los ciclistas se les inyectaba sangre de ternera, lo que traía como consecuencia que salgan disparados y corriendo como bestias en busca de la línea de llegada.

Sin embargo, no quiero pasar por alto el alto grado de hipocresía imperante en la dirigencia deportiva que ha sido precisado:

Un miembro de la nomenclatura deportiva podría responder: "El deporte, como toda actividad profesional, conlleva riesgos, pero no se trata de sumarle a la actividad más riesgos de los que la actividad indefectiblemente tiene que tener. Por eso hemos prohibido el dopaje". Es en realidad un argumento muy sólido. Pero se puede sin embargo confrontarlo también de manera sólida y robusta haciendo notar que las organizaciones internacionales que rigen los destinos del deporte por otra parte aceptan, por no decir fomentan, conductas riesgosas en los atletas. Prohíben, sí, el dopaje. Pero al mismo tiempo organizan competiciones de acuerdo a programas que son físicamente imposibles de cumplir, con exigencias excesivas incluso para los deportistas de élite, a no ser que se dopen.

$(\ldots)$

Se percibe aquí una doble moral por la nomenclatura del deporte. La autoinmolación del atleta (compartir a pesar de estar seriamente lesionado) otorga un carácter heroico a la competencia $y$, por supuesto, constituye buena publicidad para el negocio del deporte. Ese no es, sin embargo, el caso con el dopaje, por lo menos mientras sea rechazado por la mayoría de los aficionados al deporte.

$(\ldots)$

¿No es esta una actitud cínica? Por un lado, se rechaza al deporte como práctica. Pero, por otro lado, se aplaude su fruto. (Tamburrini, 2014 pp.170-171)

\section{CON ESTA SÍ, CON ESTA NO}

Es de notorio conocimiento que a todos los deportistas no se les mide con el mismo rasero. Ello depende en muchas oportunidades de las disciplinas deportivas en las que se encuentren involucrados. Así tenemos que en el ciclismo apenas producida una sospecha al atleta se le baja de la bicicleta. Sera esa la razón por la cual los atletas que ocupan los puestos siguientes al involucrado en un caso de dopaje se hacen los de la vista gorda? No resulta extraño el hecho de 
que no presenten ningún reclamo. Esto tiene una relación directa con el reexamen que puede hacer el Comité Olímpico Internacional de las muestras. Pero no solamente se deben hacer exámenes en las competencias o de manera aleatoria en los entrenos. Se debe llevar a cabo una labor de docencia: explicándoles a los deportistas los graves riesgos que conllevan para su salud la ingesta voluntaria de los productos químicos que permiten acceder a sus cuerpos. Se debe emprender un proceso de conciencia y de tolerancia cero. Podríamos citar esa canción popular que anota que: la conciencia me dice que no la debo tomar, pero el corazón indica que si debo.

Pasemos a otro ejemplo. En el mas popular de los deportes se mide de manera distinta este tipo de situaciones. Al capitán de la selección nacional se le aplico una suspensión por un periodo de tiempo que incluía el Campeonato Mundial Rusia 2018 y se le levanta la suspensión para que pueda participar pivoteando la línea de ataque del combinado patrio (llegando incluso a anotar un gol ante el combinado australiano); mientras que en España a Carlos Gurpegui jugador vasco del Athletic de Bilbao en el año 2002 se le impone una sanción de 2 años de alejamiento de los terrenos de juego, la que sin embargo se deja sin efecto luego de 6 semanas, lo que permite que el deportista pueda seguir compitiendo por tres años más.

\section{MIENTE QUE ALGO QUEDA}

En ese razonamiento lógico no esta de mas señalar que por la misma naturaleza del ser humano resulta difícil reconocer o asumir culpas cuando se ha cometido una falta. Los deportistas buscan que el resguardo que les brinda la presunción de inocencia.

Podemos referirnos entre otras cosas:

Fijémonos que la regla obliga al juez a interpretar situaciones de deficiencia de prueba en favor de la inocencia, pero no concreta cuando ha de considerarse que la prueba es deficiente. $\mathrm{Ni}$ habla de "sospechas" ni de ningún otro concepto análogo. Y cuando se habla de "duda razonable", precisamente ese adjetivo refleja la libertad interpretativa del juez y le otorga una gran laxitud al concepto (Nieva, 2013 p.73)

Un claro ejemplo de lo expuesto precedentemente es el caso del tenista argentino Mariano Puerta quien luego de 15 años de haber arrojado positivo para el dopaje en un torneo (Roland Garros) valido por el Grand Slam de tenis reconoce haber mentido en aquella oportunidad cuando fue consultado por su responsabilidad o inocencia. Cabe señalar que dicho deportista integraba la llamada generación dorada del tenis argentino que se puso como meta la obtención de la Copa Davis, pero que vio manchada su trayectoria por sonados casos de dopaje en dos de los cuales fue detectada la responsabilidad del referido deportista.

Puerta después de perder con Rafael Nadal la final de dicho evento paso en el lapso de cuatro meses de "héroe" a "tramposo deportivo". Fue castigado con la devolución de $\$ 887,000$ dólares que había recibido como concepto de premios por haber llegado a la final y a una suspensión de 8 meses luego rebajados a 2 por haberse detectado en su sangre el consumo de etilefrina.

Lo que no queda muy claro es que si el motivo de la reducción de la condena era por cuanto la cantidad consumida de etilefrina era 50 veces por debajo de la mínima para sustentar un incremento en el rendimiento deportivo por que se le sanciona.

El tema de la mentira se da en este caso por cuanto el atleta negó desde un primer momento haber consumido cualquier tipo de sustancia prohibida y inculpó a su anterior pareja Sol Estévanez ya que según señaló el haber tomado agua en el mismo vaso en el que ella había ingerido (supuestamente sin su conocimiento) Effortil un producto que calma dolores propios de la menstruación fue el origen 
de su dopaje ya que el mismo contiene etilefrina. Luego de 15 años recién manifiesta que dicha versión de los hechos era falsa.

\section{EL DOPAJE DE ESTADO: CUANDO LOS JUSTOS PAGAN POR PECADOS AJENOS}

Haciendo un poco de historia podemos traer el recuerdo de lo que aconteció con el equipo de natación de la extinta República Democrática Alemana en las olimpiadas de Montreal en 1976. Habían participado como conjunto en trece competiciones de las once en que participo. Tuvieron que consumirse varios calendarios para que se reconozca que lo consiguieron a la ingesta de fármacos prohibidos, avalados por la complacencia de una política estatal que permitió que lo hicieran para poder utilizar al deporte como una plataforma de réditos políticos.

En los precisos momentos en que me encuentro redactando este artículo, el Comité de Revisión de Cumplimiento a solicitud de la Agencia Mundial Antidopaje (AMA) ha dictaminado cuatro años de suspensión en toda competición deportiva internacional para Rusia. Ello de suyo, incluye a las Olimpiadas, Paralímpicos y Juegos Mundiales. Ello se produce como consecuencia directa al hecho que en un laboratorio moscovita se alteraron los resultados contenidos en las muestras antidopaje. Las recomendaciones contenidas en un documento de 26 folios habían sido remitidas al Comité Ejecutivo quien ha tomado la decisión final en la ciudad de Lausana (Suiza). Se ha logrado establecer que la Agencia Antidopaje Rusa (RUSADA) en los datos del Laboratorio de Moscú que comprenden el periodo 2012-2015 resultaban incompletos por no ser auténticos al no respetar las reglas mundiales antidopaje. Ello implica dos cosas: i) que durante ese lapso Rusia no podrá organizar ninguna competición deportiva y ii) que no se izará su bandera.

Sin embargo, como no se puede perjudicar a inocentes los deportistas rusos que puedan acreditar que no están contaminados (esto es que su nombre no aparezca en el Informe que consigna la alteración de muestras y resultados), en modo alguno con el tema del doping podrán participar en las competencias como neutrales. No está por demás señalar dos cosas: i) que en el 2015 la Federación Rusa ya registraba un antecedente al haber sido suspendida en competiciones atléticas; y ii) que la suspensión no abarca a la Eurocopa 2020 donde ya habían conseguido boleto y San Petersburgo había sido designada como localidad. Obviamente con la pandemia del codavid-19 el evento ha quedado postergado hasta nueva fecha.

\section{EL CASO DEL VENTOLIN}

Si bien es cierto que el salbutamol es un broncodilatador que se usa para tratar a los pacientes que sufren de asma, lo real y concreto es que su uso está parcialmente restringido en las prácticas deportivas. La pregunta se cae de madura: ¿qué ocurre con aquellos deportistas que consumen el producto bajo prescripción médica? En el caso del inhalador se necesita haber hecho más de 16 inhalaciones por día para que las mismas sean consideradas dopaje. Cada inhalación equivale al consumo de 100 microgramos de salbutamol. El tope de consumo por día no debe exceder de los 1600 microgramos. Los efectos del medicamento una vez ingerido son inmediatos: i) disminuyen la obstrucción de las vías respiratorias y ii) facilitan la respiración.

Un caso emblemático resulto ser el de la patinadora chilena Carolina Santibáñez quien fue autorizada por el Comité Olímpico Chileno $(\mathrm{COCH})$ a participar en los Juegos Panamericanos de Rio pese a haber consumido salbutamol. Ella fue exonerada de toda responsabilidad por haber manifestado que lo hizo por padecer bronquitis y haber presentado todas las recetas médicas que acreditaban su versión. Aunque parezca increíble se le quiso sancionar por el hecho de no haber solicitado 21 días antes una excepción terapéutica, la respuesta de la deportista fue más clara que el agua: en ese plazo uno no sabe si se va a enfermar. Nos encontramos ante una flagrante vulneración del repertorio de derechos que involucran a la tutela efectiva de sus intereses. 
Sostener lo contrario implica vulnerar la seguridad jurídica y la predictibilidad de las resoluciones. La facultad sancionadora de los tribunales deportivos no puede ser en modo alguno una espada de Damocles que penda sobre la cabeza de los deportistas.

Al respecto se dice:

Por tanto, no es preferible absolver a cinco, diez, cien o mil culpables antes que condenar a un inocente. Y, desde luego, tampoco sería preferible condenar a mil inocentes antes que absolver a un culpable, como demasiadas veces piensa la sociedad dependiendo de cuál sea el delito, No hay más que condenar a quien condenen las pruebas. $Y$ absolver a quien las evidencias presenten como inocente. (Nieva, 2013 p.167)

\section{LOS IMPLANTES Y LAS PRÓTESIS O LA DELGADA LÍNEA ENTRE LO PERMITIDO Y LO PROHIBIDO}

Hasta el día de hoy se sigue discutiendo si las marcas mundiales (100, 200 y 400 metros planos) logradas por el atleta paralímpico Oscar Pistorius se debieron al hecho de correr con prótesis transtibiales hechas a base de fibras de carbono por el fabricante Ossur de nacionalidad islandesa. Aunque nos parezca tirado de los cabellos pensarlo: se han presentado casos de atletas que de manera voluntaria se han roto un dedo en el pie y/o con el fin de estimular su presión sanguínea han lesionado miembros insensibilizados de su cuerpo. A este tipo de doping se le ha venido a llamar el boosting. La pregunta es: ¿puede valer tanto una presea?, nos encontramos en la época de la trampa absoluta y del vale todo por ganar; seguimos aplaudiendo y premiando cada vez con mayor frecuencia a deportistas tramposos en los podios. Podemos hacer algo o simplemente nos quedamos de brazos cruzados y seguimos formando parte del sistema. Se han visto casos de deportistas a los que la medalla les era entregada en su domicilio semanas después de concluido el evento deportivo al haberse comprobado que el atleta premiado había ingerido sustancias prohibidas. No era acaso lo justo que se le hubiese premiado ante una tribuna rebosante de público que lo ovacionara. Solo eso quería apuntar.

\section{DOPAJE QUÍMICO DE SEGUNDA GENERACIÓN}

La primera etapa del dopaje también conocida como "dopaje químico" conto con una participación activa de los atletas que elaboraban sus rutinas alimentarias guiados por profesionales de la medicina. Era un dopaje que si bien es cierto no era supervisado medicamente se apoyaba en conocimientos de medicina. Sobre la segunda etapa del dopaje químico se indica:

Que, respecto a la segunda etapa del dopaje químico, los productos y tratamientos químicos poseen una naturaleza más compleja, sus efectos se producen más a largo plazo y son más peligrosos para la salud del deportista. Por ello, su empleo no podía realizarse de modo doméstico, sino "medicalizado", es decir, controlado y realizado por médicos y especialistas. (Pérez, 2017 p.92).

\section{FAMOSOS MARCADOS POR EL DOPING}

Existen decenas de casos de deportistas famosos que han dado resultados positivos en las pruebas de dopaje que se les han realizado. Nombres que han manchado y avergonzado los logros que han obtenido y a quienes se les ha sometido posteriormente al escarnio público de retirárseles las medallas y trofeos obtenidos. Pero también es preciso indicar que se han producido casos en que, a razón inversa se señalaba a otros atletas como responsables de haber ingerido sustancias que les ayudaban a mejorar su rendimiento deportivo. Baste como ejemplo el nombre de Florence Griffith-Joyner (triple medallista de oro en las Olimpiadas de Seúl 1988 y record mundial en 100 
y 200 metros planos) a quien sin mayor prueba que su contextura física se le sindico como tal. Fernández (2018) acota:

Florence Griffith-Joyner, la Marilyn Monroe negra, como la llamaba un diario italiano, acababa de asombrar al mundo. Había corrido los 100 metros llanos de los Juegos Olímpicos de Seúl 88 más rápido que muchísimos hombres y como jamás podría volver a hacerlo una mujer. Era la diosa de las pistas. Sin embargo, a un especialista local le bastó ver sus músculos en fotografías para afirmarle a este cronista que esa mujer corría drogada. (p.147).

Lamentablemente si de algo tenemos certeza es que en nuestro país han desaparecido cuatro cosas: la clase media, la posibilidad de ahorro, nuestra capacidad de asombro y la presunción de inocencia. Todos los días a través de los medios de comunicación masiva podemos apreciar como se rompen cadenas de custodia y se impone como medalla la presunción de culpabilidad: usted es culpable hasta que demuestre que estoy equivocado. El mundo jurídico al revés.

Nieva (2019) es claro cuando precisa lo siguiente

Sin embargo, en el proceso penal se aplica la presunción de inocencia, es decir, se absuelve, incluso cuando la prueba sí que es suficiente, pero quedan dudas sin resolver, lo que se traduce en unas deficiencias que no impedirían al juez valorar la prueba según su propia convicción y criterio en cualquier otro proceso. Pero, sin embargo, esa íntima convicción es insuficiente para condenar porque la duda no se ha disipado, y así lo exigen, al menos teóricamente, las leyes. (2013 p.68)

\section{DOLO Y CULPA}

El Derecho Penal nos enseña que cuando el actor no tiene intención de generar las consecuencias que su actitud conlleva se configura la culpa, por cuanto en su mentalidad no se había producido el propósito de generar daño con su actitud; mientras que el dolo se presenta cuando si existía una intención de producir el daño. Ese daño está vinculado indefectiblemente al concepto del delito. En el deporte cuando manejamos los conceptos de dolo y culpa en relación al dopaje, estamos entrando a tratar de determinar si ha existido o no el propósito de alterar el resultado de una competencia deportiva a través de prácticas mal habidas y sancionadas por el reglamento.

Uno de los casos que más se recuerdan se produjo en la ciudad de Boston durante el transcurrir del XV Campeonato Mundial de Fútbol de1994 al concluir el encuentro donde la selección argentina derrotaba por 2 goles a 1 a su par de Nigeria. Sobre otro caso famoso:

Maradona tomó un descongestionante adquirido en una farmacia de Villa Devoto, en Buenos Aires. Quise saber cómo estaba compuesto el fármaco y, efectivamente, contenía efedrina, una sustancia prohibida. Ya está, me dije a mí mismo. Quince meses de suspensión a partir del próximo partido a disputar y escándalo nacional. Le tocó justo a él, no sé. Hubo dirigentes argentinos que podían haber orinado, según ellos, en lugar de Maradona y no lo hicieron. ¿Qué hay de verdad o no? No se puede saber. A mí, me sonó que el repechaje fue un crédito que no había que gastarse. De ahí en más, si cualquier jugador se lo gastaba sería severamente sancionado. (Macaya, 2018 pp.158-159)

¿Fue dolo o culpa? Sabia o no el deportista los componentes químicos de la efedrina. Si nos dejamos guiar por sus antecedentes estimo que la respuesta sería afirmativa. El que para muchos es considerado como el más grande deportista en el marco de la rama que practica, en su desarrollo personal ha venido generando un proceso autodestructivo que parece no tener límites. 
Cabe agregar que entre las personas allegadas al deporte que criticaron la irresponsabilidad de Maradona en dicha competencia esta Sebastiao Lazaroni - director técnico de la verde amarelha en Italia 1990- que señaló que el atleta sabía perfectamente durante el torneo en tierras yanquis que estaba consumiendo productos prohibidos, y que, si alguna duda quedaba, bastaba con observar en un reproductor de video el desaforado festejo de su gol a Grecia en dicha cita ecuménica.

\section{LA AGENCIA MUNDIAL ANTIDOPAJE}

La World Anti-Doping Agency (AMA) se fundó en Lausana el 10 de noviembre de 1999 con la finalidad de promover y coordinar la lucha contra el dopaje en el deporte en la esfera internacional y se integró de forma paritaria por representantes de organizaciones deportivas, gubernamentales e intergubernamentales. Configura una fundación sin obligaciones y su creación depende del apoyo del Comité Olímpico Internacional (COI) a una iniciativa colectiva. Es una organización sin fines de lucro. Su objetivo es liberar al deporte de toda marca de dopaje.

Podemos referir a Tamburrini (2014) cuando infiere lo siguiente

¿Qué es dopaje? Dopaje es en realidad la lista de sustancias prohibidas. Lo que no ha sido incorporado a esa lista oficial que marca la Agencia Mundial Antidopaje (WADA por sus siglas en inglés) está permitido, lo que está incorporado ahí, es dopaje. Ahora ¿cómo se incorporan sustancias o métodos de entrenamientos a esa lista? Hay tres criterios que deben ser cumplidos. Uno es que la sustancia o el método de entrenamiento en cuestión conlleve una ventaja en el rendimiento deportivo. La segunda es que sea un riesgo para la salud de quien emplea ese método de entrenamiento o consume esa sustancia. Y la tercera es que sea contrario al ethos o el espíritu del deporte. Esto es así oficialmente. (2014, p.116)

\section{EL CÓDIGO AMA}

En el año 2003 la AMA elabora el Código Mundial Antidopaje a fin de sintonizar la normativa internacional sobre dopaje. Pérez Triviño (2017) señala que "con la creación de la AMA y del Código, la lucha antidopaje tomó la forma de una carrera de policías y ladrones altamente tecnologizada en la que el signo distintivo de la misma era la tolerancia cero ante los tramposos, los cuales debían ser capturados y apartados del deporte." (p.102).

En ese orden de ideas, podemos indicar que el programa antidopaje a nivel global tiene como carta fundamental a la descrita en el párrafo precedente. Su finalidad es enfrentar al doping con todos los elementos y armas que tengan que ver con dicha lucha.

Este Código busca en pocas palabras, conseguir resultados justos a través del fomento de una cultura deportiva libre del flagelo de la droga. Establece como una de sus funciones primordiales la de noticiar a los atletas de los riesgos que el uso de las drogas conlleva para su salud. Sancionar a todos los que se mienten a si mismos, equiparando el piso para que el mismo se encuentre parejo.

Para este cuerpo normativo son infracciones que se consideran dopaje:

a) Que en la muestra de un atleta se encuentren sustancias prohibidas

b) El intento de uso o uso de un método o sustancia prohibida por un deportista

c) No permitir el deportista que se le practique un control antidoping

d) Que se le incumpla con brindar información que permita la localización de un deportista

e) La manipulación de cualquier parte del proceso de dopaje

f) El tráfico o posesión de métodos o sustancias prohibidas

g) La administración de sustancias tanto fuera como dentro de los eventos deportivos 
h) La complicidad para contribuir a conseguir la infracción de todas estas normas

i) La asociación de un deportista con cualquier persona de apoyo que este cumpliendo un periodo de suspensión

\section{EL DOPING EN LOS MUNDIALES DE FUTBOL}

Los casos de futbolistas que recurrieron al dopaje han surtido de contenido a páginas poco envidiables de los Mundiales de Fútbol para no extenderme demasiado en otros torneos de alta competición. Así tenemos por ejemplo que durante el desarrollo de la X Copa del Mundo disputada en la República Federal Alemana en 1974 (por esos años aún existía el Muro de Berlín) el futbolista haitiano Ernst Jean-Joseph durante el encuentro que su país natal perdió con Italia 3 a 1 arrojo en su control de orina positivo al Phenylmetrazin. Jean-Joseph sostuvo haber ingerido una medicina que lo ayudaba a controlar el asma que sufría, lo que fue desmentido por el médico de la delegación. Eran los tiempos en que Jean Claude Duvalier ejercía la presidencia en Haití. Al culminar el encuentro futbolístico el jugador fue secuestrado por la Policía Secreta de su país, golpeado salvajemente y conducido al aeropuerto. Se le condenó a dos años de reclusión por el cargo de haber deshonrado al país.

En 1978 en la ciudad de Córdoba se enfrentaban las selecciones nacionales de Perú con la favorita Escocia. Mientras que en la cancha los peruanos festejaban una trabajada victoria por 3 a 1, el puntero izquierdo escoces Willie Johnstone daba positivo a la Fencanfamina (recuperador de fatiga). Tuvieron que transcurrir ocho años para que en el campeonato mundial disputado en tierras aztecas el español Ramón María Calderé diera positivo a la efedrina; sin embargo al demostrar que había ingerido un jarabe con prescripción médica se le condenó a un partido de suspensión y a una multa de 25000 euros. La gran pregunta es si existía una autorización del facultativo porque se le castiga.

Hasta que llegamos al evento citado precedentemente del 25 de junio de 1994 en que tras el encuentro disputado entre las selecciones de Argentina y Nigeria al que hemos aludido precedentemente, da positivo al producto efedrina Diego Maradona a quien se le expulsa del mundial y se le suspende de toda competición deportiva por el periodo de 15 meses. Por única respuesta el volante de la selección argentina dejó esta frase: "No quiero dramatizar, pero créanme que me cortaron las piernas". Nadie podría sospechar que al momento de despedirse de los campos el mismo señalara que "La pelota no se mancha", cuando estaba claro que era Maradona el que había fracturado al fútbol con su conducta antideportiva. Es triste ver el estado actual en que se encuentra dicho deportista por el uso indiscriminado de fármacos. Su cerebro dispara para todos lados, pero casi nunca acierta en el punto de mira.

El escritor uruguayo Galeano (2007) aporta al respecto lo siguiente

Jugó, venció, meó, perdió. El análisis delató efedrina y Maradona acabó de mala manera su Mundial del 94. La efedrina, que no se considera droga estimulante en el deporte profesional de los Estados Unidos, y de muchos otros países, está prohibida en las competencias internacionales. (2007 p.232)

El caso que acabamos de señalar ha tratado de ser justificado por los argentinos desarrollando teorías disparatadas de complot para tratar de encontrar una explicación racional a la conducta del ídolo de barro. Se llego al extremo de buscar culpables en el seno de la FIFA y de otros gobiernos que no podían permitir que un renegado del sistema levante el máximo trofeo de selecciones.

Se Maradona é um notório antisistema, alimentam-se lendas como a de que a ditadura argentina náo o deixu ser campeáo dentro de casa ou que seus casos de doping foram fruto de conspiracóes dos italianos e da Fifa. (2014:344) 


\section{$(\ldots)$}

Outro mito que Maradona gosta de alimentar: o de tersido vitima de armacáo nos dois mas famosos casos de doping da sua carreira -as suspensóeas por uso de cocaína, em 1991, e por consumo de efedrina durante a Copa do Mundo dos Estados Unidos, em 1994. (Rossi, 2014 p.356)

\section{LOS CONTROLES ANTIDOPING DE LA FIFA}

La Federación Internacional de Fútbol Asociado ha establecido la manera en que se lleva a cabo el proceso para detectar si un atleta ha hecho alguna de las trampas que guardan relación con el tema que nos ocupa. Una vez identificado el deportista por el Oficial debe ser notificado acerca de las razones del procedimiento y la forma en que se va a realizar el mismo, indicándosele cuáles son sus derechos y obligaciones. Se le entregan dos frascos cerrados de plástico rotulados con las letras "a" y "b"; tanto el oficial como el deportista deben comprobar el buen estado de los mismos. Se requieren como mínimo 90 mililitros para que sea aceptada la muestra de orina, que se extraen con la autorización del deportista para que el oficial lo observe mientras micciona. Si no se alcanza el mínimo requerido se le solicitara al futbolista una nueva muestra.

Una vez ello, las muestras son llevadas a un laboratorio de la Agencia Mundial Antidopaje (AMA) con una cadena de custodia determinada por la FIFA. Las muestras no se abren hasta que se proceda al análisis de las mismas por personal del laboratorio. Los resultados se hacen en razón a la muestra "a", mientras que la "b" solamente se abrirá en caso de ser solicitada una contraprueba. Al jugador únicamente se le informa cuando el análisis arroja un resultado positivo.

Una de mis plumas preferidas, la del oriental Galeano (2015) aporta que:

Diego Armando Maradona fue adorado no sólo por sus prodigiosos malabarismos sino también porque era un dios sucio, pecador, el más humano de los dioses. Cualquiera podía reconocer en él una síntesis ambulante de las debilidades humanas, o al menos masculinas: mujeriego, tragón, borrachín, tramposo, mentiroso, fanfarrón, irresponsable.

Pero los dioses no se jubilan, por humanos que sean.

Él nunca pudo regresar a la anónima multitud de donde venía. La fama que lo había salvado de la miseria, lo hizo prisionero. Maradona fue condenado a creerse Maradona y obligado a ser la estrella de cada fiesta, el bebé de cada bautismo, el muerto de cada velorio. Más devastadora que la cocaína es la exitoína. Los análisis, de orina o de sangre, no delatan esta droga. (2015 p.299)

\section{EL DOPAJE AL REVÉS}

A situaciones inusuales, especulaciones sorprendentes. Con ese titular podríamos tratar de comenzar a entender los pronunciamientos que se efectúan cuando apreciamos de modo subjetivo hechos deportivos que no son moneda común.

Conceptos científicos que ayudar a esclarecer lo que antes estaba oscuro, tomando nota de lo que se sabía antes y lo que hoy se conoce:

Primero el deporte era concebido solamente para varones, luego, a mitad de siglo se incorporan las mujeres, pero segregadas. ¿Por qué se hace? Porque el conocimiento científico de la época no permitía más que diferenciar entre hombres y mujeres. Y ¿por qué fue necesario hacerlo? Porque el sexo biológico es un indicador, sobre todo de la incidencia de andrógenos en el individuo que compite. Es decir, un hombre por lo general tiene muchos más andrógenos, en particular testosterona, que cualquier mujer, siempre en términos generales. Y la testosterona, 
en los deportes más remunerables, los deportes que se generaron en el ideal bélico de la antigüedad donde la fuerza, la altura, la velocidad son premiadas y son admiradas, es decisiva justamente para desarrollar esas características físicas. La explosividad, la fuerza, la masa muscular dependen de la testosterona, de los andrógenos.

$(\ldots)$

Con el avance de la ciencia, sobre todo la genética, se ve que en realidad no tiene sentido mirar los genitales, ni siquiera la identidad genética del individuo. Lo que tiene sentido ver es el índice de los andrógenos y en particular de testosterona que el individuo tiene, independientemente de su sexo biológico. Porque puede haber hombres que tengan menor nivel de testosterona que Caster Semenya o que cualquier mujer intersexual. (Tamburrini, 2014 pp.108-109)

Cabe aterrizar nuestro comentario para ahora si referirnos al caso de esta atleta sudafricana que fue discriminada por su condición física sin que haya existido de su parte consumo de cualquier sustancia prohibida en catálogos deportivos, con el fin de mejorar su rendimiento en las pistas.

El pecado mortal que le imputo la Santa Inquisición dirigencial fue el que a sus 18 años había en Berlín se había permitido alzarse con la presea dorada en los 800 metros planos en los Mundiales de Atletismo. Como era de esperarse, empezaron a saltar los fariseos que sin prueba alguna empezaron a acusar de dopaje a la atleta tan solo por su apariencia física. La acusaron de ser un hombre. Ese cuarto poder que es la prensa llego a tildarla de hermafrodita. El matutino londinense Daily Telegraph fue más allá: la denigró señalando que no poseía útero y que internamente contaba con testículos en lugar de ovarios, siendo aquellos los que le producían la testosterona.

Cuando los argumentos se acaban, los insultos despuntan. Que fácil es apuntar al flanco más débil. Después de tales vituperios el rendimiento de la deportista no volvió a ser el mismo.

Conceptos que parten de una sociedad machista en la que imperan la violencia de genero y una afectación a la sincronía en detrimento de los derechos del sexo femenino. Las mujeres han sido muchas veces estigmatizadas y el deporte ha brindado varios casos de muestra.

Rivero (2014) también aporta al respecto cuando señala lo siguiente

(...) se daban circunstancias como la ocurrida en Londres 1948, cuando la atleta holandesa Francina Elsje Blankers Koen, que ganó cuatro títulos olímpicos en atletismo, fue denominada la "ama de casa voladora", porque era madre de dos niños. Una valorización que, obviamente, no se realizaba con los atletas masculinos. En el deporte siguen reproduciéndose esquemas "sexistas" alrededor del mérito deportivo femenino, mientras en otros espacios sociales se ha producido una mayor feminización de los contenidos, aunque solo sea en lo formal. Un ejemplo podría ser el ejército, una institución eminentemente masculina -con importantes características históricas de profundo sentido machista- que en su proyección propagandista ha incorporado el papel de la mujer como atractivo de la renovación inclusiva de sus valores y de sus reflejos con la sociedad. Al menos como publicidad. (2014 p.43)

Aclarado, lo precedente regresemos al tema que nos ha convocado.

\section{¿Y POR CASA CÓMO ANDAMOS?}

La ley de promoción y desarrollo del deporte incorpora como un órgano asesor independiente del Instituto Peruano del Deporte a la Comisión Nacional Antidopaje que entre sus subfunciones tiene las de prevenir, controlar y luchar contra el uso de sustancias no permitidas en competiciones deportivas: además de tener entre otra de sus funciones la de luchar contra los métodos no permitidos por ley para generar un rendimiento deportivo más allá del que normalmente pueda generar un atleta. 
Este organismo lo preside un representante del Instituto Peruano del Deporte y esta integrado por un representante de las federaciones deportivas y uno de las siguientes dependencias: Ministerio de Educación, Ministerio de Salud, Comité Olímpico Peruano, Colegio Médico del Perú y el Colegio Químico Farmacéutico del Perú. Estos cargos se desempeñan sin retribución alguna, por el periodo de un ciclo olímpico (4 años), con la opción de ser reelegidos por única vez.

Dentro de las funciones también tenemos las de controlar el dopaje en torneos de carácter nacional e internacional, elaborar y custodiar la lista de métodos (sustancias prohibidas en competencias y entrenamientos), así como también las excepciones terapéuticas permitidas y sancionar a los atletas que incurran en conductas reñidas con la honradez deportiva. Conductas traicioneras que enlodan el marco del deporte.

\section{FAIRPLAY}

El término Fair Play viene del idioma ingles y significa Juego Limpio. En sentido amplio viene a representar el respeto que deben guardar los deportistas hacia los rivales, compañeros de equipo, árbitros y espectadores en general. En sentido concreto significa que no se debe acudir a actitudes reñidas con la actividad deportiva para alterar los resultados de una competición.

Uno de los más bellos ejemplos al respecto lo brindó en una competencia atlética el deportista español Iván Fernández Anaya quien estaba siendo relegado a un segundo plano por el medallista en las Olimpiadas de Londres, el keniata Abel Mutai quien en una tarde fría de Navarra se confunde y se para en seco antes de haber traspuesto la línea de meta. El corredor hispano al percatarse de ello, lejos de cruzar la meta se frena y ayuda al africano a recoger lo que por mérito deportivo le correspondía. Parecía que el personaje hidalgo de la novela cervantina había dejado su lucha contra los molinos de viento y se convertía en un tipo como la gente. Obviamente que si preguntábamos por los auspiciadores en esos momentos se nos hubiera dicho que los buscáramos en una clínica adonde se los habían llevado por un ataque al corazón al percatarse de lo ocurrido. Jaque mate del amateurismo al profesionalismo. Game Over.

\section{Rivero (2014) acerca de lo expuesto precedentemente acota lo siguiente}

En la noticia sobre Iván Fernández, una lectora de El País señalaba en los comentarios de la noticia de la versión digital del diario: "A mí desgraciadamente me pasó cuando era una cría (ir segunda en una carrera y tener a alguien por delante con problemas no deportivos) y aunque mi primera reacción fue esa que dices, mi padre empezó a berrearme para que siguiera, para que ganara. Y me dieron una medalla que me supo siempre a mierda. Es más, desde ese día le tengo ojeriza a todo lo que significa competición. Efectivamente, algunas victorias no te dejan dormir, ni te dejan sentir orgullosa de haber ganado. Para mí, es prioritario, poder mirarme por la noche en el espejo y estar a gusto con lo que veo". (2014:77)

En buena fuente podemos sostener que la idea del juego limpio representa que todos los deportistas compitan bajo las mismas reglas. Pretende sancionar a todos los mentirosos que pateando el tablero le juegan sucio al deporte.

\section{CONCLUSIONES}

El cada vez más desarrollado concepto del profesionalismo que engloba el pago de cantidades exorbitantes de dinero a los vencedores de las competencias deportivas se ha convertido en el principal estímulo para que aparezcan cada vez con mayor frecuencia deportistas tramposos que tratan de sacar ventajas en sus rendimientos deportivos en detrimento de sus rivales, sin medir los riesgos que ello podría conllevar contra su salud. 
Se hace necesario que las autoridades deportivas insistan con el concepto del Juego Limpio, promoviendo el mismo a nivel globalizado y imponiendo sanciones cada vez más drásticas a los deportistas que incluyan a los dirigentes, entrenadores, representantes y/o a cualquier otra persona a la que se le encuentre responsabilidad, pudiendo llegar incluso a separarlos definitivamente de toda práctica deportiva.

Las autoridades deportivas deben tratar de avanzar cada vez más en técnicas y métodos de control de dopaje deportivo, por cuanto como hemos podido revisar en el presente artículo son cada vez más las modalidades con que los tramposos pretender ganar esta desigual batalla.

Resulta penoso comprobar como cada vez con mayor frecuencia los deportistas permiten que ingresen sustancias extrañas en sus organismos, ponderando réditos deportivos inmediatos a pesar que en un futuro no muy lejano, las mismas los puedan conducir directamente a la muerte.

El deporte es nuestro no de los tramposos. En esto debe jugar un papel importante los medios de comunicación masiva fomentando campañas de salud y bienestar y quitando de sus cámaras a los deportistas sancionados por doping dejando de ventilar sus casos, por más famosos que sean. Es penoso ver como los periodistas ruegan a los atletas para que les concedan una entrevista. El día que contribuyan a hacerlos más terrenales todo cambiara para bien.

\section{REFERENCIAS Y CITAS BIBLIOGRÁFICAS}

- Fernández Moores, E. (2018). Juego, Luego Existo. Escribir el Deporte. Sudamericana.

- Galeano, E. (2007). El fútbol a sol y sombra. Siglo XXI Editores.

- Galeano, E. (2015) Espejos. Una historia casi universal. Siglo XXI Editores.

- Gamero, E. (2012). Fundamentos de Derecho Deportivo. (Adaptado a Estudios No Jurídicos). Tecnos.

- Gutiérrez, J. (2018) Deporte y Derechos Fundamentales. Marcial Pons.

- Macaya, E.(2018) Mis Mundiales. De Suecia 58 a Rusia 2018. Planeta.

- Mosset, J. (Director) e Iparraguirre, C. (Coordinador). (2011) Tratado de Derecho Deportivo. Tomo II. Rubinzal-Culzoni Editores.

- Nieva, J. (2013) La duda en el proceso penal. Marcial Pons.

- Pérez, J. (2017). El dopaje y las nuevas tecnologías. El nuevo paradigma del deporte. Editorial UOC.

- Pérez, José y Cañizares, E. (Coordinadores) (2018). Deporte y Derechos. Editorial Reus.

- Real Academia Española. (2019). Diccionario de la Lengua Española. Edición del Tricentenario. Actualización.

- Rivero, J. y Tamburrini C. (2014). Del juego al Estadio. Reflexiones sobre ética y deporte. Clave Intelectual.

- Rossi, J. y Mendes L. (2014) Guia Politicamente Incorrecto do Futebol. Texto Editores Ltda.

Fecha de recepción: 23 de octubre de 2020

Fecha de aceptación:06 de noviembre de 2020 